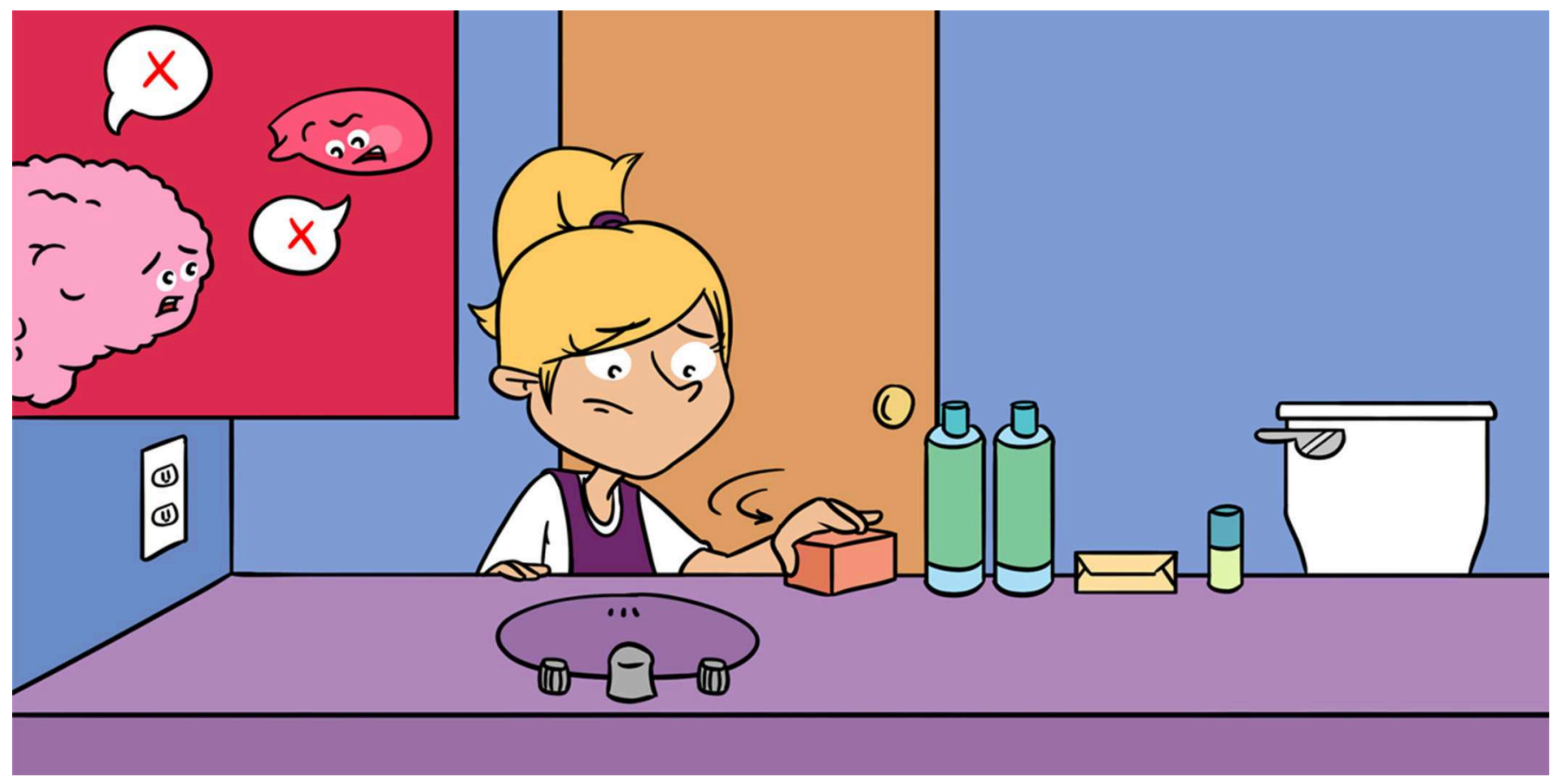

\title{
WHAT IS OBSESSIVE COMPULSIVE DISORDER?
}

\section{Pedro Morgado ${ }^{1,2,3 *}$ \\ ${ }^{1}$ Life and Health Sciences Research Institute (ICVS), School of Health Sciences, University of Minho, Braga, Portugal ${ }^{2}$ ICVS-3Bs PT Government Associate Laboratory, Braga, Portugal \\ ${ }^{3}$ Hospital de Braga, Braga, Portugal}

YOUNG REVIEWER:

SIENA COLLEGE AGE: 15
Obsessive-compulsive disorder is a brain disorder characterized by unwanted and repetitive thoughts that cause intense worry (called obsessions) and/or by repetitive behaviors that patients perform to try to relieve the suffering caused by obsessions (called compulsions). Treatments exist and include medication and psychotherapy (therapeutic conversations between a professional and the patient). New treatments using electromagnetic stimulation and/or a technique of real-time brain imaging are also being developed. In this article, we will describe the symptoms of this disorder, its causes, and the different treatments available. Learning about this disorder is very important, so that we will be able to identify and treat it appropriately.

\section{WHAT IS OBSESSIVE-COMPULSIVE DISORDER?}

Obsessive-compulsive disorder (OCD) is a brain disorder affecting $1-3 \%$ of the population worldwide. It affects men and women equally 


\section{OBSESSIONS}

Unwanted and repetitive thoughts, urges, or mental images that cause anxiety and suffering.

\section{COMPULSIONS}

Repetitive behaviors to reduce suffering provoked by obsessions. and it usually starts during childhood, adolescence, or early adulthood. It is uncommon for people to get OCD for the first time after the age of 30. As the name tells us, OCD is characterized by the presence of obsessions, compulsions, or both [1].

Obsessions are repetitive, unwanted, uncontrollable, and persistent thoughts (such as doubt about whether something they have done is good enough, or fear of germs), urges (such as saying something nasty), or mental images (such as violent scenes) that appear in the mind of the patient, causing intense anxiety and suffering. These worries just pop into the patient's head and can be hard to get rid of.

To reduce the suffering and distress caused by obsessions, the patient can be compelled to perform repetitive behaviors (called compulsions). Compulsions (also called rituals) can include checking and re-checking whether something is closed or locked, or washing and cleaning too much, or they can be mental acts, such as repeating a word or counting something. Patients feel driven to perform these compulsions in response to their obsessions.

It is important to know that everyone can experience obsessions and compulsions occasionally. Obsessions, such as the thought, "did I really lock the door to the house?," and compulsions, such checking and rechecking your answers when taking a test at school, are usually good things, because they improve our performance and reduce the chance of errors. To cross over into OCD, obsessive thoughts must occur for more than $1 \mathrm{~h}$ each day and/or interfere significantly with daily life.

\section{TYPES OF OBSESSIONS AND COMPULSIONS}

Obsessions and compulsions generally involve several common themes, which are summarized in Table 1.

\section{WHAT CAUSES OCD?}

OCD is a brain disorder caused by multiple factors that are not completely known nor understood. In some cases, OCD is genetic (inherited through the mother's or father's genes), but in other cases it is related to certain infections (in rare situations, some children develop obsessive symptoms after a severe throat infection, for example), traumatic events (such as threatening situations, abuse, or bullying), and/or chronic stress [2]. We already know that OCD is not caused by anything that the patient or his/her parents did "wrong."

The brain works like a computer, with multiple networks connecting brain regions that are responsible for different functions. We have 


\section{Table 1}

Examples of obsessions and compulsions.

\section{CORTEX}

The folded surface of brain.

\section{BASAL GANGLIA}

Group of nuclei located under the cerebral cortex.

\begin{tabular}{lll}
\multicolumn{1}{c}{ Category } & Examples of obsessions & Associated compulsions \\
\hline Contamination & $\begin{array}{l}\text { Feeling of being dirty } \\
\text { Fear of being contaminated }\end{array}$ & $\begin{array}{l}\text { Washing and cleaning rituals } \\
\text { Avoidance of } \\
\text { touching something } \\
\text { Doubt }\end{array}$ \\
Doubting if the door is locked & $\begin{array}{l}\text { Checking and re-checking if it } \\
\text { is locked }\end{array}$ \\
Symmetry & $\begin{array}{l}\text { The feeling that something has } \\
\text { to be arranged "just right" }\end{array}$ & $\begin{array}{l}\text { Putting things in just the right } \\
\text { order }\end{array}$ \\
Superstition & $\begin{array}{l}\text { Something is lucky or unlucky, } \\
\text { bad or good, safe or harmful }\end{array}$ & $\begin{array}{l}\text { Touching, tapping, or stepping } \\
\text { in an unusual way }\end{array}$ \\
Forbidden thoughts & $\begin{array}{l}\text { Repetitive thoughts about acting } \\
\text { inappropriately }\end{array}$ & $\begin{array}{l}\text { Avoiding situations out of fear } \\
\text { of acting inappropriately }\end{array}$ \\
\hline
\end{tabular}

Table 1

complex systems for every function. For example, one brain network is responsible for acquiring and managing the data that comes in from our senses, another is responsible for creating and managing our emotions, another is responsible for movements, and another is responsible for creating, managing and prioritizing our thoughts.

In OCD, the communication system between parts of the brain, namely the orbitofrontal cortex and the basal ganglia, is disrupted and the brain makes mistakes when processing and prioritizing information.

The orbitofrontal cortex is responsible for using information from the senses to make decisions, and anticipating the result of our life choices. In OCD, this region is hyperactivated and detects errors and dangers where there is not anything wrong.

The basal ganglia controls movements and thinking, and acts as a control system that filters and stops anxious thoughts. In OCD, the basal ganglia fail to control the errors and dangers wrongly identified by the orbitofrontal cortex, which makes the patient overwhelmed by his or her thoughts and actions (Figure 1).

\section{HOW IS OCD DIAGNOSED AND TREATED?}

Many people suffering from OCD recognize that their obsessions and compulsions are unreasonable, which makes them feel ashamed and embarrassed. The shame and embarrassment often stop some OCD patients from seeking treatment, which prolongs their suffering.

The diagnosis of OCD is done by doctors who can recognize the symptoms and signs of the disorder. The doctors diagnose OCD by asking specific questions. When the disease is identified, patients may feel relieved to know what is causing their suffering.

Treatments for OCD usually involve a combination of medication and psychotherapy. The medications most often used to treat OCD 
Figure 1

Brain regions affected in OCD. Studies suggest that communication between the front part of the brain (the orbitofrontal cortex) and a deeper structure of the brain (the basal ganglia) is disrupted in OCD.

Figure 2

The OCD cycle. Obsessions are intrusive thoughts or images that can be very disturbing. Because of the anxiety created by the obsession, compulsions are developed in order to relieve this anxiety. Antidepressants act by decreasing obsessions and their related anxiety, while psychotherapy (also called CBT or cognitive behavioral therapy) helps patients to learn how to resist to compulsions.

\section{SEROTONIN}

Chemical substance used to transmit messages between neurons

(neurotransmitter).
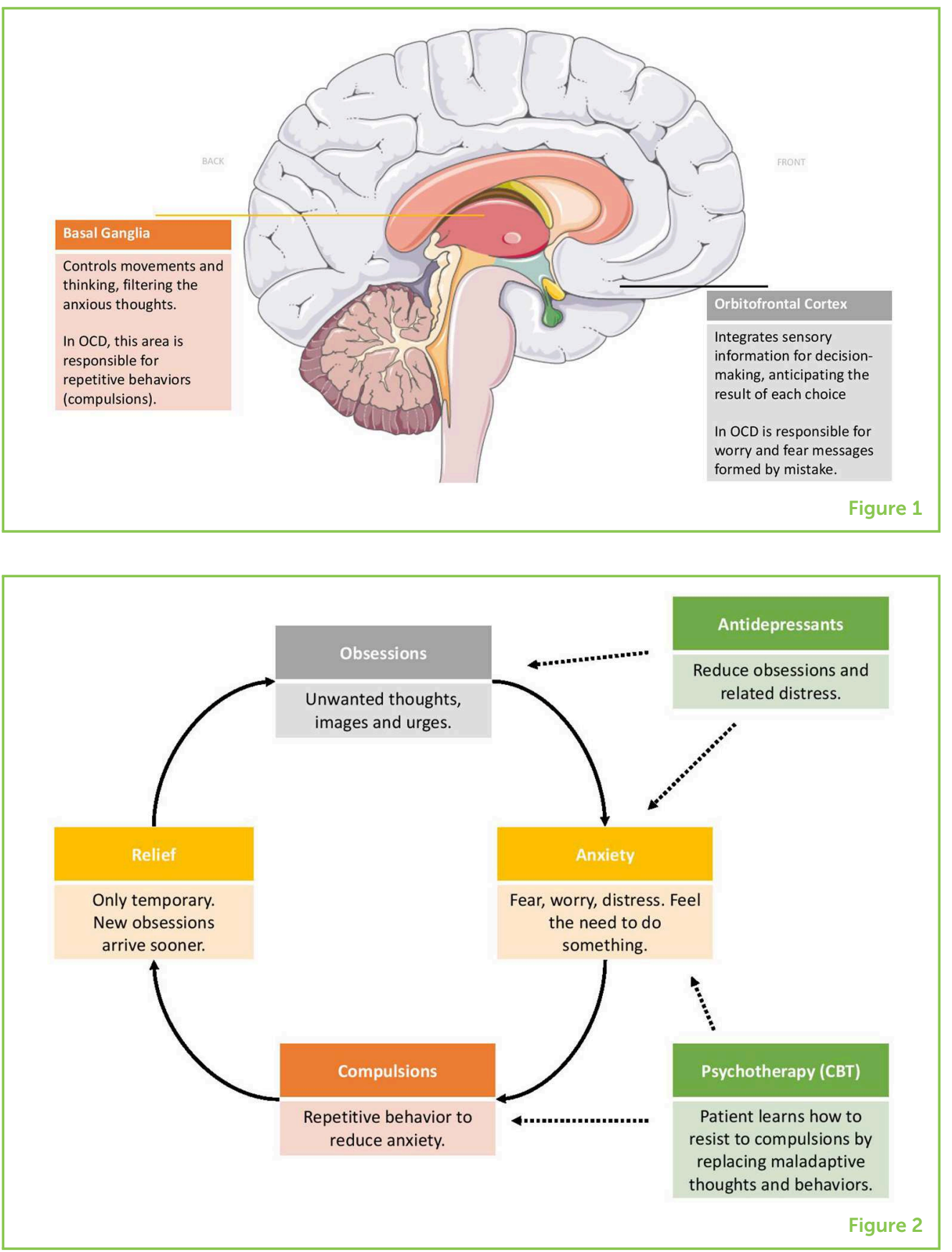

are called serotonin reuptake inhibitors (SRIs), which work to fix the hyperactivation of the orbitofrontal cortex and to reduce the anxiety caused by the obsessions (Figure 2).

Psychotherapy can also be effective in the treatment of OCD. Psychotherapy is a therapeutic conversation between a professional (a therapist, psychologist, or psychiatrist) and the patient that can help to identify, understand, and resolve problems. The most effective psychotherapy is called cognitive behavioral therapy (CBT), which focuses on identifying and replacing inappropriate thoughts and behaviors to help patients resist their compulsions. In therapy sessions, patients learn more about OCD and how it works. Because the 
rituals patients perform keep their OCD going strong, patients learn and practice ways to ignore worrisome thoughts and to face the fear caused by their obsessions. By avoiding compulsions, patients eventually learn to stop the cycle of OCD (Figure 2), allowing their brain networks to work in a healthier way again.

Some research groups are working to develop new ways to treat OCD. The new treatments being tested include the electromagnetic stimulation of specific brain regions (to enhance or reduce the activation of these regions), and feedback using real-time brain imaging to provide the patients with information about the activation of the brain regions involved in OCD, and new forms of psychotherapy, such as online psychotherapy or group psychotherapy (Figure 2).

\section{CONCLUSIONS}

OCD is a common disorder that affects young people. It is characterized by repetitive and unwanted thoughts, images, and urges that cause worry (obsessions) and by repetitive behaviors that are used to control the anxiety provoked by obsessions (compulsions). In OCD, there is a dysfunction in the communication system of the brain, which causes problems with information processing. Treatments for OCD are available and include medications and psychotherapy. New treatments are being developed to provide better ways of helping those suffering from OCD.

\section{ACKNOWLEDGMENTS}

Figure 1 was created using Servier Medical Art under Creative Commons Attribution 3.0 Unported License.

\section{REFERENCES}

1. Richter, P. M., and Ramos, R. 2018. Obsessive-compulsive disorder. Continuum (Minneap Minn). 24:828-44. doi: 10.1212/CON.0000000000000603

2. Morgado, P., Freitas, D., Bessa, J. M., Sousa, N., and Cerqueira, J. J. 2013. Perceived stress in obsessive-compulsive disorder is related with obsessive but not compulsive symptoms. Front. Psychiatry 4:21. doi: 10.3389/fpsyt.2013.00021

SUBMITTED: 24 April 2019; ACCEPTED: 20 November 2019;

PUBLISHED ONLINE: 09 December 2019.

EDITED BY: Daniel F. Hermens, Sunshine Coast Mind and Neuroscience Thompson Institute, University of the Sunshine Coast, Australia

CITATION: Morgado P (2019) What Is Obsessive Compulsive Disorder? Front. Young Minds 7:138. doi: 10.3389/frym.2019.00138 


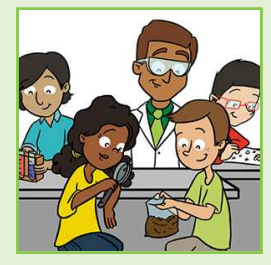

CONFLICT OF INTEREST: The author declares that the research was conducted in the absence of any commercial or financial relationships that could be construed as a potential conflict of interest.

COPYRIGHT ( 2019 Morgado. This is an open-access article distributed under the terms of the Creative Commons Attribution License (CC BY). The use, distribution or reproduction in other forums is permitted, provided the original author(s) and the copyright owner(s) are credited and that the original publication in this journal is cited, in accordance with accepted academic practice. No use, distribution or reproduction is permitted which does not comply with these terms.

\section{YOUNG REVIEWER}

\section{SIENA COLLEGE, AGE: 15}

We are high-school students at Siena College. We have a variety of interests and enjoy studying sciences and the humanities. We were pleased to contribute to this interesting article.

\section{AUTHOR}

\section{PEDRO MORGADO}

I am a Professor at the School of Medicine, University of Minho (Braga, Portugal) and a Psychiatrist at Hospital de Braga. Since early, I was fascinated by the human mind and wanted to understand how it works. As a researcher, I am interested in understanding how chronic stress affects our decisions and emotions, inducing disorders, such as OCD. When I am not working, I can be found spending time with partner, family, and friends. I like museums, running, reading, and traveling the world. You can follow my research activities (and other stuff) via Twitter: www.twitter.com/pedromorgado *pedromorgado@med.uminho.pt. 